\title{
Effect of Midazolam on Sedation and Hemorheology in Elderly Patients with Acute Cerebral Infarction
}

\author{
HAO MAAND LINGLING WEN ${ }^{1 *}$
}

Department of Anesthesiology, 'Department of Intensive Care Unit, Hunan Cancer Hospital, Hunan, Changsha 410013, China

Ma et al.: Effect of Midazolam on Sedation and Hemorheology

\begin{abstract}
To explore the effect of midazolam in the treatment of senile acute cerebral infarction is the main objective. the patients were divided into observation group $(n=55)$ and control group $(n=55)$ by envelope method, the control group was given routine treatment, the observation group was given midazolam on the basis of the control group, the time required for sedation, mean arterial pressure, heart rate and so on were observed. There was no significant difference in sedation time between the observation group and the control group $(p>0.05)$. The awakening time of the observation group was $(8.10 \pm 1.54) \mathrm{min}$, which was significantly shorter than that of the control group $(\mathbf{p}<\mathbf{0 . 0 5})$. The mean arterial pressure and heart rate of the observation group before anesthesia induction (T1) and $30 \mathrm{~min}$ after anesthesia (T2) were $(\mathbf{9 2 . 0 2} \pm 3.05) \mathrm{mmHg}$ and $(\mathbf{9 1 . 1 4} \pm 2.93)$ $\mathrm{mmHg},(87.70 \pm 4.82)$ times/min and $(\mathbf{8 3 . 0 2} \pm 5.01)$ times/min, respectively, which were significantly lower than those of the control group $(\mathrm{p}<\mathbf{0 . 0 5})$. The blood oxygen difference $\left[\mathrm{D}(\mathrm{a}-\mathrm{j} v) \mathrm{O}_{2}\right]$ and cerebral oxygen uptake rate $\left(\mathrm{ERO}_{2}\right)$ at $\mathrm{T} 1$ and $\mathrm{T} 2$ in the observation group were $(4.56 \pm 0.67)$ and $(3.02 \pm 0.82),(\mathbf{2 0 . 2 0} \pm 6.73)$ $\%$ and $(16.80 \pm 4.11) \%$, respectively, which were significantly lower than those in the control group $(\mathrm{p}<0.05)$. The scores of mini-mental state examination at $1 \mathrm{~d}$ and $3 \mathrm{~d}$ after operation in the observation group were $(25.11 \pm 2.10)$ and $(26.04 \pm 1.92)$, respectively, which were significantly higher than those in the control group $(p<0.05)$. The serum $C$-reactive protein and tumor necrosis factor alpha in the observation group were significantly lower than those in the control group at $1 \mathrm{~d}, 3 \mathrm{~d}$ and $7 \mathrm{~d}$ after operation $(\mathrm{p}<0.05)$. Midazolam has a good sedative effect in the elderly patients with acute cerebral infarction, reducing brain oxygen metabolism and stabilizing hemorheology.
\end{abstract}

Key words: Midazolam, acute cerebral infarction, sedation, hemorheology

Acute cerebral infarction is a common clinical disease caused by thrombosis and arteriosclerosis in cerebral vessels. Local ischemic necrosis of brain tissue is easy to cause infarction ${ }^{[1,2]}$. The brain tissue is characterized by low Adenosine Triphosphate (ATP) reserve, high metabolism and high oxygen consumption and the brain tissue is the most hypoxic tissue in the body ${ }^{[3]}$. Once there is insufficient blood supply in the brain, the normal brain cells and tissues will also be affected, secondary damage occurs and a vicious cycle forms ${ }^{[4]}$. After cerebral vascular occlusion, the ability of brain to absorb oxygen increased and the amount of brain oxygen decreased significantly. Due to the insufficient cardiopulmonary compensatory ability of elderly patients, severe edema and necrosis occurred in the cerebral ischemic area in a short time ${ }^{[5,6]}$. Midazolam is a kind of benzodiazepines with strong water solubility. Its therapeutic effect has been clinically recognized. It is commonly used as an anticonvulsant and for sedative

*Address for correspondence

E-mail: 6100936@qq.com effect in clinic. However, there are few studies on the role of midazolam in patients with acute cerebral infarction ${ }^{[7,8]}$. This study aims to explore the application effect of midazolam in the treatment of elderly patients with acute cerebral infarction.

\section{MATERIALS AND METHODS}

\section{General information:}

Selected 110 elderly patients with acute cerebral infarction treated in our hospital from May 2015 to May 2020. Inclusion criteria: Comply with the guidelines for diagnosis and treatment of acute ischemic stroke in China (2014) ${ }^{[9]}$ formulated by Neurology Branch of Chinese Medical Association and confirmed by Computed Tomography (CT) and Magnetic Resonance Imaging (MRI); patients aged $\geq 60 \mathrm{y}$; informed consent of family members of patients. Exclusion criteria: Combined with other important organ diseases such as liver and kidney Malignant Tumors and immune system 
diseases; have a history of mental illness. The patients were divided into the observation group $(n=55)$ and the control group $(n=55)$ by envelope method and the general data of the two groups were compared (Table $1)$.

TABLE 1: COMPARISON OF GENERAL DATA OF THE TWO GROUPS

\begin{tabular}{|c|c|c|c|c|c|c|c|c|c|}
\hline \multirow[b]{2}{*}{ Group } & \multirow[b]{2}{*}{ Cases } & \multirow[b]{2}{*}{ Male (\%) } & \multirow[b]{2}{*}{ Age (y) } & \multirow{2}{*}{$\begin{array}{c}\text { Body mass } \\
\text { index }(\mathrm{kg} / \\
\left.\mathrm{m}^{2}\right)\end{array}$} & \multirow{2}{*}{$\begin{array}{l}\text { NIHSS } \\
\text { scores } \\
\text { (points) }\end{array}$} & \multicolumn{4}{|c|}{ Infarction area } \\
\hline & & & & & & $\begin{array}{c}\text { Left } \\
\text { hemisphere }\end{array}$ & $\begin{array}{c}\text { Right } \\
\text { hemisphere }\end{array}$ & Brain stem & Cerebellum \\
\hline $\begin{array}{l}\text { Observation } \\
\text { group }\end{array}$ & 55 & $30(54.55)$ & $72.30 \pm 9.81$ & $22.83 \pm 2.31$ & $21.01 \pm 4.22$ & $24(43.64)$ & $22(40.00)$ & $6(10.91)$ & $3(5.45)$ \\
\hline Control group & 55 & $(58.18)$ & $70.44 \pm 9.15$ & $22.95 \pm 3.00$ & $20.01 \pm 5.12$ & $25(45.45)$ & $24(43.64)$ & $4(7.27)$ & $2(3.64)$ \\
\hline$t / \chi^{2}$ & & 0.148 & 1.028 & -0.235 & 1.118 & \multicolumn{4}{|c|}{0.707} \\
\hline$p$ & & 0.701 & 0.306 & 0.815 & 0.266 & \multicolumn{4}{|c|}{0.871} \\
\hline
\end{tabular}

NIHSS=National Institutes of Health Stroke Scale

\section{Treatment and anesthesia methods:}

Methods: The control group was treated with dexmedetomidine hydrochloride injection (Chinese medicine standard word H20110085). Manufacturer: Jiangsu Hengrui Pharmaceutical Co., Ltd pump speed is $0.2 \sim 0.7 \mu \mathrm{g} / \mathrm{kg} / \mathrm{min}$, continuous $30 \mathrm{~min}$. Administered edaravone injection (H20050280). Manufacturer: Nanjing Xiansheng Dongyuan Pharmaceutical Co., Ltd. Specification: $30 \mathrm{mg}$ : $20 \mathrm{ml} / \mathrm{branch}) 1$ edaravone injection dissolved in $100 \mathrm{ml}$ normal saline, twice a day for patients with intravenous drip. Oral administration of atorvastatin calcium tablets (Chinese medicine standard word H20051407). Manufacturer: Pfizer Pharmaceutical Co., Ltd.), $20 \mathrm{mg}$ each time, once/night. Antiplatelet aggregation, inhibition of brain edema and improvement of brain cell nutritional metabolism and other nutritional support were routinely used.

The observation group was given midazolam intravenous sedation on the basis of conventional treatment. The first dose of 2 5 mg was infused at the rate of 0.03 0.3 $\mathrm{mg} / \mathrm{kg}$ for $20 \sim 30 \mathrm{~s}$ and then intermittent administration was performed $2 \mathrm{~min}$ later to achieve satisfactory deep sedation. The depth of sedation was evaluated by Ramsay score. When the score reached grade 3 and 4 , it was considered to be sufficient sedation and the intravenous drip rate was maintained at $0.03 \sim 0.2 \mathrm{mg} /$ $(\mathrm{kg} / \mathrm{h})$.

\section{Test method:}

The Heart Rate (HR) and Mean Arterial Pressure (MAP) during T1 and T2 were observed and recorded by a multifunctional detector. The time required for sedation in the observation group and the control group was observed. The multi-parameter Electrocardiogram (ECG) monitor was used to monitor the arterial oxygen content $\left(\mathrm{CaO}_{2}\right)$ and internal jugular venous oxygen content $\left(\mathrm{CjvO}_{2}\right)$ of ECG and $\mathrm{D}$ (a-jv) $\mathrm{O}_{2}=\mathrm{CaO}_{2}$ $\mathrm{CjvO}_{2}{ }^{[10]}$. Brain oxygen uptake rate $\left(\mathrm{ERO}_{2}\right)=\mathrm{D}(\mathrm{a}-\mathrm{jv}) \mathrm{O}_{2} /$ $\mathrm{CaO}_{2}{ }^{[11]}$. Mini-Mental State Examination (MMSE) was used to evaluate the postoperative cognitive function of patients. The total score was 30 and the score $<27$ were divided into cognitive dysfunction.

On the $1^{\text {st }}, 3^{\text {rd }}$ and $7^{\text {th }} \mathrm{d}$ after operation, $3 \mathrm{ml}$ fasting venous blood was collected and centrifuged at 2000 $\mathrm{r} / \mathrm{min}$ for $10 \mathrm{~min}$. The supernatant was collected to obtain the serum to be tested. The levels of serum C-Reactive Protein (CRP) and Tumor Necrosis Factor Alpha (TNF- $\alpha)$ were detected by Enzyme-Linked Immunosorbent Assay (ELISA). The ELISA kit was purchased from R\&D Company of the United States. The standard substance was prepared according to the instructions of the kit. The absorbance value of the standard substance was measured under the microplate reader. The standard curve was plotted with the standard substance concentration as the abscissa and the absorbance value as the ordinate. Then the sample to be tested was subjected to gradient dilution and the absorbance value of the sample hole was measured under the same conditions. The absorbance value of the sample hole was substituted into the standard curve to obtain the concentration of the sample to be tested.

\section{Statistical treatment:}

Statistical Package For The Social Sciences (SPSS) 22.0 software was used for data analysis. MAP, HR and other data were expressed as $(\overline{\mathrm{x}} \pm \mathrm{s})$. Repeated measures, analysis of variance or $t$ test was used to compare the differences between groups. Gender and other data were expressed as n (\%), 2 tests was used to analyze the difference between groups. $\mathrm{p}<0.05$ indicated that the difference was statistically significant. 


\section{RESULTS AND DISCUSSION}

Sedative effect of the two groups was compared. The time difference between the observation group and control group was not significant $(p>0.05)$; the wake up time after withdrawal in the observation group was $(8.10 \pm 1.54) \mathrm{min}$, was significantly shorter than the control group $(\mathrm{p}<0.05)$ (Table 2$)$.

MAP, HR in different periods was compared. The T1, T2 period MAP, HR was significantly lower than the control group $(\mathrm{p}<0.05)$; no statistical difference in the T0 period MAP, HR comparison ( $>0.05$ ) (Table 3 ).

Brain oxygen metabolism in two groups in different periods was compared. The T1, T2-period D (a-jv) $\mathrm{O}_{2}$ and $\mathrm{ERO}_{2}$ were significantly lower than the control group $(\mathrm{p}<0.05)$; the T0-period $\mathrm{D}(\mathrm{a}-\mathrm{jv}) \mathrm{O}_{2}$ and $\mathrm{ERO}_{2}$ and control groups ( $>0.05)$ (Table 4$)$.

Postoperative MMSE score between the two groups was compared. The MMSE score was significantly higher at $1 \mathrm{~d}, 3 \mathrm{~d}$ than at controls $(\mathrm{p}<0.05)$; no MMSE scores at $7 \mathrm{~d}$ between observers and controls $(\mathrm{p}>0.05)$ (Table 5).

Postoperative CRP, TNF- $\alpha$ level between the two groups was compared. Serum CRP, TNF- $\alpha$ was significantly lower at $1 \mathrm{~d}, 3 \mathrm{~d}$ and $7 \mathrm{~d}(\mathrm{p}<0.05)$ (Table 6).

TABLE 2: COMPARISON OF THE SEDATION EFFECTS OF THE TWO GROUPS

\begin{tabular}{lccc}
\hline Group & Cases & Sedation time (min) & $\begin{array}{c}\text { Wake up time after } \\
\text { discontinuation (min) }\end{array}$ \\
\hline Observation group & 55 & $30.11 \pm 5.20$ & $8.10 \pm 1.54$ \\
Control group & 55 & $31.05 \pm 6.01$ & $11.72 \pm 2.01$ \\
$\mathrm{t}$ & & -0.877 & -10.602 \\
$\mathrm{p}$ & & 0.382 & 0.000 \\
\hline
\end{tabular}

TABLE 3: COMPARISON OF MAP, HR IN TWO GROUPS OF DIFFERENT PERIODS

\begin{tabular}{|c|c|c|c|c|c|}
\hline Index & Group & Cases & T0 & T1 & T2 \\
\hline \multirow{2}{*}{ MAP $(\mathrm{mmHg})$} & Observation group & 55 & $94.20 \pm 3.50$ & $92.02 \pm 3.05^{*}$ & $91.14 \pm 2.93^{*}$ \\
\hline & Control group & 55 & $94.12 \pm 4.32$ & $104.40 \pm 4.11$ & $95.50 \pm 3.65$ \\
\hline \multicolumn{6}{|c|}{$\mathrm{F}$ time $\times$ group $=34.432, \mathrm{~F}$ time $=15.543, \mathrm{~F}$ group $=12.211$} \\
\hline \multicolumn{6}{|c|}{$p<0.05, p<0.05, p<0.05$} \\
\hline \multirow{2}{*}{ HR (Beats/min) } & Observation group & 55 & $81.29 \pm 5.03$ & $87.70 \pm 4.82^{*}$ & $83.02 \pm 5.01 *$ \\
\hline & Control group & 55 & $82.20 \pm 4.88$ & $101.20 \pm 5.10$ & $89.29 \pm 4.88$ \\
\hline \multicolumn{6}{|c|}{$\mathrm{F}$ time $\times$ group $=31.201, \mathrm{~F}$ time $=16.611, \mathrm{~F}$ group $=14.022$} \\
\hline \multicolumn{6}{|c|}{$p<0.05, p<0.05, p<0.05$} \\
\hline
\end{tabular}

Note: *Compare $p<0.05$ with the controls

TABLE 4: COMPARISON OF MAP, HR IN TWO GROUPS OF DIFFERENT PERIODS

\begin{tabular}{|c|c|c|c|c|c|}
\hline Index & Group & Cases & T0 & $\mathrm{T} 1$ & T2 \\
\hline \multirow{2}{*}{$\mathrm{D}(\mathrm{a}-\mathrm{j} \mathrm{v}) \mathrm{O}_{2}$} & Observation group & 55 & $7.13 \pm 1.12$ & $4.56 \pm 0.67^{*}$ & $3.02 \pm 0.82^{*}$ \\
\hline & Control group & 55 & $7.08 \pm 1.08$ & $5.93 \pm 1.02$ & $4.81 \pm 1.00$ \\
\hline \multicolumn{6}{|c|}{$\mathrm{F}$ timexgroup $=31.022, \mathrm{~F}$ time $=20.014, \mathrm{~F}$ group $=9.882$} \\
\hline \multicolumn{6}{|c|}{$p<0.05, p<0.05, p<0.05$} \\
\hline \multirow{2}{*}{$\mathrm{ERO}_{2}(\%)$} & Observation group & 55 & $35.40 \pm 7.82$ & $20.20 \pm 6.73^{*}$ & $16.80 \pm 4.11^{*}$ \\
\hline & Control group & 55 & $34.48 \pm 8.03$ & $28.81 \pm 5.80$ & $20.03 \pm 3.70$ \\
\hline \multicolumn{6}{|c|}{$\mathrm{F}$ time $\times$ group $=29.804, \mathrm{~F}$ time $=18.892, \mathrm{~F}$ group $=10.003$} \\
\hline \multicolumn{6}{|c|}{$p<0.05, p<0.05, p<0.05$} \\
\hline
\end{tabular}

Note: *Compare $p<0.05$ with the controls 
www.ijpsonline.com

TABLE 5: THE POSTOPERATIVE MMSE SCORE COMPARISON BETWEEN THE TWO GROUPS

\begin{tabular}{lcccc}
\hline Group & Cases & 1 d postoperative & 3 d postoperative & 7 d postoperative \\
\hline Observation group & 55 & $25.11 \pm 2.10$ & $26.04 \pm 1.92$ & $28.51 \pm 1.02$ \\
Control group & 55 & $21.18 \pm 1.92$ & $24.32 \pm 2.00$ & $28.22 \pm 1.11$ \\
$\mathrm{t}$ & & 10.243 & 4.601 & 1.427 \\
$\mathrm{p}$ & & 0 & 0 & 0.157 \\
\hline
\end{tabular}

TABLE 6: COMPARISON OF POSTOPERATIVE CRP AND TNF- $\alpha$ IN TWO GROUPS

\begin{tabular}{lccccc}
\hline Index & Group & Cases & 1 d postoperative & 3 d postoperative & 7 d postoperative \\
\hline & Observation group & 55 & $21.13 \pm 5.02$ & $16.62 \pm 3.11$ & $9.13 \pm 2.11$ \\
& Control group & 55 & $29.43 \pm 6.65$ & $25.58 \pm 4.06$ & $14.53 \pm 1.93$ \\
CRP $(\mathrm{mg} / \mathrm{l})$ & $\mathrm{t}$ & & -7.388 & -12.993 & -14.005 \\
& $\mathrm{p}$ & & 0 & 0 & 0 \\
& Observation group & 55 & $21.10 \pm 3.22$ & $15.58 \pm 3.01$ & $10.43 \pm 2.05$ \\
& Control group & 55 & $26.61 \pm 3.54$ & $22.43 \pm 2.95$ & $15.52 \pm 2.18$ \\
TNF- $\alpha(\mathrm{ng} / \mathrm{l})$ & $\mathrm{t}$ & & -8.539 & -12.054 & -12.614 \\
& $\mathrm{p}$ & & 0 & 0 & 0 \\
\hline
\end{tabular}

Acute cerebral infarction is a disease with high clinical risk, with high morbidity and mortality. Brain tissue damage causes secondary damage and vicious circle, which will cause more serious damage to brain cells and brain tissue ${ }^{[12]}$. Studies have shown that when the degree of cerebral vascular occlusion is above the range of cerebral oxygen absorption, the oxygen consumption of brain tissue decreases, the level of lactic acid increases and the ischemic brain tissue appears edema or necrosis ${ }^{[13]}$. Therefore, it is urgent to improve the tolerance of brain tissue to hypoxia and reduce the damage of ischemic tissue or cells in patients with acute cerebral infarction ${ }^{[14]}$. Elderly patients with acute cerebral infarction usually have insufficient understanding of things and weak control of the body. After the onset, they are prone to strong anxiety, fear and stress response to the disease itself or the environment (such as elevated blood pressure), which makes some elderly patients have poor tolerance and poor therapeutic effect in the process of retreatment. It is necessary to use sedatives safely and effectively, maintain the patient's vital signs which are relatively stable, alleviate the ideal state of anxiety.

The results of this study showed that the control group was given conventional treatment, midazolam sedation observation group patients were monitored before treatment, $30 \mathrm{~min}$ after treatment with MAP and HR. The MAP and HR in the observation group were significantly lower than those in the control group before treatment and $30 \mathrm{~min}$ after treatment. There was no significant difference in the time required for sedation between the two groups, indicating that both can achieve sedation in a short time. The awakening time of the observation group was significantly shorter than that of the control group. The reason was that midazolam played a role in sedation, anticonvulsant and muscle relaxation by acting on $\gamma$-aminobutyric acid receptors in the central nervous system. In addition, midazolam can stabilize respiration and blood pressure to a certain extent and can provide physiological sleep state to the human body, almost without inhibiting respiration, which makes the vital signs of patients remain stable during sedation.

Inhibition of cerebral oxygen metabolism is the self-protection mechanism of the body. Cerebral blood supply and cerebral metabolism constitute the physiological process of cerebral circulation. The two match and work together and cerebral blood supply participates in the process of cerebral metabolism circulation $^{[15]}$. Quantitative analysis of cerebral blood supply and cerebral metabolism will help to assess the ischemic and hypoxic state of brain tissue and evaluate the therapeutic effect of drugs. The oxygen uptake rate in the brain can quantitatively reflect the degree of brain metabolism and D (a-jv) can be calculated by $\mathrm{CaO}_{2}$ as the percentage of oxygen inhaled by brain neurons ${ }^{[16]}$. When cerebral blood flow decreases, the normal metabolic process can only be maintained by increasing the intake of blood oxygen in brain tissue and nerve cells. Therefore, it is necessary to find measures 
to reduce the content of $\mathrm{O}_{2}$ in cerebral venous return blood ${ }^{[17]}$. The results showed that the $\mathrm{O}_{2}$ and $\mathrm{ERO}_{2}$ of $\mathrm{D}$ (a-jv) at T1 and T2 periods in the observation group were significantly lower than those in the control group. The reason may be that under physiological $\mathrm{pH}$ conditions, midazolam can quickly enter the central nervous system, interact with $\gamma$-aminobutyric acid receptor, enhance its inhibitory effect on neurotransmitters, greatly reduce cerebral blood flow and return to normal levels, thereby reducing intracranial pressure and improving cerebral oxygen metabolism. The results of this study showed that the MMSE scores of the observation group at $1 \mathrm{~d}$ and $3 \mathrm{~d}$ after operation were significantly higher than those of the control group. There was no significant difference in MMSE scores between the two groups at $7 \mathrm{~d}$ after operation. Midazolam can improve the brain blood supply, improve oxygen consumption in the ischemic area, stabilize HR and blood pressure and stabilize the vital signs of patients, thereby enabling patients to have a good mental state.

Inflammatory factors play an important role in acute cerebral infarction. The increase of CRP and TNF- $\alpha$ levels can aggravate the disease ${ }^{[18,19]}$. In this study, midazolam was given to the elderly patients with acute cerebral infarction for sedation. It was found that the levels of CRP and TNF- $\alpha$ in patients receiving midazolam sedation were lower than those in patients receiving conventional treatment at $1 \mathrm{~d}, 3 \mathrm{~d}$ and $7 \mathrm{~d}$ after operation. The reason is that midazolam improves the degree of local inflammatory cascade reaction and reduces the level of inflammatory factors by reducing the level of neurochemotactic protein in cerebrospinal fluid.

The sedative effect of midazolam is significant, which has been proved to be significant in the treatment of many diseases but its application in acute cerebral infarction is rarely studied. In previous studies, when evaluating the sedative effect of midazolam, the changes of cerebral oxygen metabolism indexes were often analyzed, because they could objectively reflect the cerebral metabolism ${ }^{[20]}$. On this basis, this study also analyzed the changes in the mental state of patients and the indicators of typical inflammatory factors and discussed the sedative mechanism of midazolam in many aspects. In this study, we analyzed that midazolam can reduce the degree of cerebral oxygen metabolism, which is beneficial to restore the blood oxygen supply of damaged brain tissue and improve the inflammatory response of the body. An appropriate amount of sedatives during the treatment can effectively reduce the patient's fear of disease or environmental changes, reduce the stress of nerve reflex, improve the mental symptoms of patients in the short term and do not affect the respiratory cycle, which is easy to be accepted by patients.

In summary, midazolam has a good sedative effect in elderly patients with acute cerebral infarction, which can reduce cerebral oxygen metabolism and stabilize hemorheology.

\section{Conflicts of interest:}

The authors declared no conflict of interest.

\section{REFERENCES}

1. Jin X, Zou Y, Zhai J, Liu J, Huang B. Refractory Mycoplasma pneumoniae pneumonia with concomitant acute cerebral infarction in a child: A case report and literature review. Medicine 2018;97(13): e0103.

2. Zhang T, Xiang L. Elevated plasma haptoglobin level as a potential marker for poor prognosis in acute cerebral infarction. Eur Neurol 2018;79(3-4):154-60.

3. Choi JI, Ha SK, Lim DJ, Kim SD, Kim SH. S100ß, matrix metalloproteinase-9, D-dimer, and heat shock protein 70 are serologic biomarkers of acute cerebral infarction in a mouse model of transient MCA occlusion. J Korean Neurosurg Soc 2018;61(5):548-58.

4. Nai Y, Liu H, Bi X, Gao H, Ren C. Protective effect of astaxanthin on acute cerebral infarction in rats. Hum Exp Toxicol 2018;37(9):929-36.

5. Jaffe TA, Winslow J, Zhang Y, Allen BC, Choudhury KR, Samei E. Automated early identification of an excessive airin-oil x-ray tube artifact that mimics acute cerebral infarct. J Comput Assist Tomogr 2019;43(1):18-21.

6. Yasukochi Y, Sakuma J, Takeuchi I, Kato K, Oguri M, Fujimaki $\mathrm{T}$, et al. Six novel susceptibility loci for coronary artery disease and cerebral infarction identified by longitudinal exome-wide association studies in a Japanese population. Biomed Rep 2018;9(2):123-34.

7. Perera AH, Rudarakanchana N, Monzon L, Bicknell CD, Modarai B, Kirmi O, et al. Cerebral embolization, silent cerebral infarction and neurocognitive decline after thoracic endovascular aortic repair. Br J Surg 2018;105(4):366-78.

8. Behme D, Gera RG, Tsogkas I, Colla R, Liman J, Maier IL, et al. Impact of time on thrombolysis in cerebral infarction score results. Clin Neuroradiol 2020;30(2):345-53.

9. Neurology branch of Chinese Medical Association. Chinese guideline for diagnosis and treatment of acute ischemic stroke, 2014. Chin J Neurol 2015;48(4):246-57.

10. Michel J, Hofbeck M, Peper AK, Kumpf M, Neunhoeffer F. Evaluation of an updated sedation protocol to reduce benzodiazepines in a pediatric intensive care unit. Curr Med Res Opin 2020;36(1):1-6.

11. Doss GA, Fink DM, Mans C. Assessment of sedation after intranasal administration of midazolam and midazolambutorphanol in cockatiels (Nymphicus hollandicus). Am J Vet Res 2018;79(12):1246-52.

12. QiaoZhen $\mathrm{X}$, AiGuo $\mathrm{M}$, Tong W, JingJing L, HaiYing L. Correlation between of small dense low-density lipoprotein cholesterol with acute cerebral infarction and carotid atherosclerotic plaque stability. J Clin Lab Anal 2019;33(6):e22891. 
13. Li QX, Zhao XJ, Peng YB, Wang DL, Dong XL, Fan HY, et al. A prospective study of comparing the application of two generation scoring systems in patients with acute cerebral infarction. Adv Ther 2019;36(11):3071-8.

14. Teng L, Meng R. Long non-coding RNA MALAT1 promotes acute cerebral infarction through miRNAs-mediated hs-CRP regulation. J Mol Neurosci 2019;69(3):494-504.

15. von Blomberg A, Kay L, Knake S, Fuest S, Zollner JP, Reif PS, et al. Efficacy, tolerability, and safety of concentrated intranasal midazolam spray as emergency medication in epilepsy patients during video-EEG monitoring. CNS Drugs 2020;34(5):545-53.

16. Jeong J, Jung K, Seo KI, Yun BC, Han BH, Lee SU, et al. Propofol alone prevents worsening hepatic encephalopathy rather than midazolam alone or combined sedation after esophagogastroduodenoscopy in compensated or decompensated cirrhotic patients. Eur J Gastroenterol Hepatol 2020;32(8):1054-61.

17. Liang P, Xu Y, Lan F, Ma D, Li K. Decreased cerebral blood flow in mesial thalamus and precuneus/PCC during midazolam induced sedation assessed with ASL. Neuroinformatics 2018;16(3):403-10.
18. Gamblin V, Berry V, Tresch-Bruneel E, Reich M, Da Silva A, Villet S, et al. Midazolam sedation in palliative medicine: retrospective study in a French center for cancer control. BMC Palliat Care 2020;19(1):1-10.

19. Pickthorn S, Terpstra E, Conde TP, Kolba J, Ali M. Use of midazolam for minimal sedation in pediatric outpatients: A Survey analysis of patient experience and parent/guardian satisfaction. S D Med 2019;72(9):414-7.

20. Park JY, Kim BJ, Lee SW, Kang H, Kim JW, Jang IJ, et al. Influence of midazolam-related genetic polymorphism on conscious sedation during upper gastrointestinal endoscopy in a Korean population. Sci Rep 2019;9(1):1-8.

This is an open access article distributed under the terms of the Creative Commons Attribution-NonCommercial-ShareAlike 3.0 License, which allows others to remix, tweak, and build upon the work non-commercially, as long as the author is credited and the new creations are licensed under the identical terms

This article was originally published in a special issue, "Diagnostic and Therapeutic Advances in Biomedical Research and Pharmaceutical Sciences"

Indian J Pharm Sci 2021:83(5)Spl issue "101-106" 